International Journal of Instruction e-ISSN: 1308-1470 • www.e-iji.net

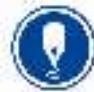

April 2021 • Vol.14, No.2

p-ISSN: 1694-609X

pp. 685-702

Article submission code

20200522155318

Received: 22/05/2020

Revision: $13 / 10 / 2020$

Accepted: 05/11/2020

OnlineFirst: 21/02/2021

\title{
Classroom Motivational Climate in Higher Education: Validation of a Model for Assessment
}

\section{Diana Abello}

Departamento de psicopedagogía, Facultad de Educación, Universidad Pedagógica Nacional, Colombia,dabello@pedagogica.edu.co

\section{Jesús Alonso-Tapia}

Departamento de psicología clínica y de la salud, Facultad de psicología, Universidad Autónoma de Madrid, Spain, jesus.alonso@uam.es

\section{Ernesto Panadero}

Facultad de Psicología y Educación, Universidad de Deusto, Funded by personal grant under Ikerbasque programme, Spain, ernesto.research@gmail.com
This study aims to adapt and validate the Classroom Motivational Climate Questionnaire and Attribution of Motivational Changes to the Teacher Questionnaire, for their administration in Higher Education and thus having adequate instruments to assess motivational climate and student preferences in this educational level. Data from 624 university students were analyzed through a Confirmatory Factor Analysis based on the original models proposed for each questionnaire. Then, a cross-validation analysis was performed for each questionnaire between two random sub-samples. Subsequently, a Path Analysis was conducted on both instruments to measure predictive validity on performance. A multigroup analysis was also conducted with two categories of students: those in their initial studies (basic) and those in practice-oriented studies (in-depth). The results confirm the factor structure for both questionnaires with configurations slightly different from those found in previous studies with high school samples. The Classroom Motivational Climate Questionnaire was found to influence performance and to identify differences in student's motivational profile depending to the year of their study.

Keywords: classroom climate, motivation, university, questionnaire, performance

\section{INTRODUCTION}

Motivation is a fundamental condition for learning to take place, and at the Higher Education level this is no exception, so the question for many researchers has been how to get students to sustain adequate levels of motivation throughout their Higher Education studies until their successful completion. (Kelmendi \& Nawar, 2016; Senior, 
et al, 2018). According to Achievement goal theory (Ames \& Archer, 1988; Nicholls, 1989), students engage in academic activities for different reasons. This fact implies the existence of different motivational orientations: a) Mastery orientation, when the student's goal is to master a skill or content; b) Performance orientation, when the students' goal is to demonstrate that they perform better in comparison to others or to the pre-established standard, and c) avoidance orientation, if students act trying not to appear less smart that their peers. In short, the students' motivational orientation influences their learning process and academic performance (Cellar, et al, 2011; Meece, Anderman, \& Anderman, 2006; Vandewalle, Nerstad, \& Dysvik, 2019).

While each student has a motivational orientation of his/her own, each particular classroom influences the type of goal the student sets specifically for that class. The students' perception of the class influences the goals they choose and allows evaluation of what is known as classroom motivational climate, a climate shaped by the teacher's actions (Alonso-Tapia, 2016; Alonso-Tapia \& Fernández-Heredia, 2008; Gutiérrez \& Tomás, 2018; Corkin, Horn \& Pattison, 2017). One of the main characteristics influencing the type of motivational orientation a student adheres to, in a given class, is marked by the way objectives or goals are structured in the classroom (Rolland, 2012).

Classroom goal structures are defined by the type of achievement objectives pinpointed by the teacher during their pedagogical practice in a learning environment. Current research has focused on three types of goal: Mastery goals, which emphasize the acquisition of knowledge or the development of competencies; performance/result goals, which emphasize demonstrating competence in comparison with others or with the standard; and avoidance goals, which emphasize not looking bad in front of others (Kadioglu \& Uzuntiryaki-Kondakci, 2014; Meece et al., 2006; Patrick, Kaplan, \& Ryan, 2011). Thus, classroom goal structures and the motivational climate are complementary concepts that facilitate the identification of how the teacher's actions influence achievement in educational environments (Bardach, Oczlon, Pietschnig, \& Lüftenegger, 2019).

The importance of the classroom motivational climate and its influence on learning processes and academic performance have been observed in several studies (Rolland, 2012; Kadioglu \& Uzuntiryaki-Kondakci, 2014; Corkin, et al., 2017). Students' perceptions of motivational climates predict the personal goals students adopt for class, so classroom climates focused on learning and mastery are considered facilitators of motivational orientations toward the same type of objective.

The motivational climate is specific to each classroom and is configured mainly through the teacher's actions (Alonso-Tapia, 2016). This fact means that teachers differ from each other in the way they organize the class activities and in their communication with the students. Besides, teachers' action patterns have motivational implications, as will be shown in the next section. Therefore, the differences pointed create a specific motivational climate for each classroom, that favors or hinders students' motivation to learn, and thus, it is important to recognize, in each classroom, how the motivational climate is actively being configured and which teacher actions are facilitating or 
hindering the generation of a motivational climate of mastery that favors learning in Higher Education classrooms.

Although the importance of identifying and working on the classroom motivational climate is widely acknowledged, studies on this construct in Higher Education are incipient. Although there are some studies on this educational domain (Ahmad \& Rana, 2011; Gutiérrez \& Tomás, 2018; Zlate \& Cucui, 2015), they are not as comprehensive as those at other educational levels, which poses questions about the motivational needs of Higher Education students in the classroom and what are the most appropriate teaching strategies to work with students in this context.

To understand the ideal characteristics of the Higher Education classroom motivational climate, it is necessary to clarify the theoretical assumptions that form the basis of "classroom motivational climate," as well as the instruments required to evaluate it.

\section{Classroom Motivational Climate}

The concept of classroom motivational climate has its roots in two sources. The first is based on the theories of goal orientation related to achievement, and the second, on the concept of school climate and its typologies.

The theory of goals related to achievement (Nicholls, 1989) proposes that the main objective in achievement contexts is to succeed in mastering a skill or knowledge or to demonstrate skill or knowledge. Within these objectives, there are two different conceptions of skill. Underlying the objective of succeeding in mastering is a conception of skill as a modifiable attribute and the product of effort, whereas where the objective is to demonstrate, skill is conceptualized as a relatively stable trait whose existence is demonstrated when one succeeds and surpasses others. Students who have the first conception seek to learn, whereas those who have the second seek to demonstrate their ability or to prevent others from perceiving that they lack ability. Although there is a personal predisposition toward one type of goal or another, it is influenced by contextual factors defining the classroom motivational climate (Ames, 1992; Alonso-Tapia, Ruiz \& Huertas, 2020), which is part of the wider school climate.

Applying organizational climate theories to the educational context has led to the definition of a school climate (Anderson, 1982), a macro-climate that includes the classroom as one of its subsystems, the place where teachers and students interact and where the teaching process takes place. The classroom climate includes more specific sub-climates (Alonso-Tapia, et al, 2020; Djigic \& Stojiljkovic, 2011; Goldenberg \& Klavir, 2017): the academic-motivational climate, the emotional climate, the disciplinary climate (all of which depend on teacher action), and the climate of coexistence or peer support Underlying this, the motivational climate is understood as the set of teacher actions that can influence the orientation of student motivation toward learning (Ames, 1992).

The existence of a motivational climate oriented toward a task or mastery is facilitated when the teacher emphasizes improving personal achievements, assessing individual effort and learning (Ames, 1992) through action guidelines, by introducing learning 
activities during their course work and at the time when the assessment takes place (Alonso-Tapia et al., 2020). When this happens, the student focuses on acquiring new skills or perfecting those they have already acquired to achieve their mastery. This climate fosters adaptive motivational responses in the student, such as greater interest and satisfaction with learning and academic activity, greater perception of self-efficacy, and attributions of effort-centered success. By contrast, a performance climate, involving the ego, occurs when the teacher encourages comparisons between one student and another, or with a regulatory standard whereby the success of students is judged in relation to the performance of others. This makes the student perceive that the academic process is oriented toward demonstrating competence, a perception generating inadaptive motivational responses, such as disinterest in learning, anxiety regarding assessment, choosing tasks based only on the probability of success, and attribution of success to ability or failure to the lack of it that leads to, perceiving ability as a stable factor.

Works such as that by Lerdpornkulrat, Koul, and Poondej (2018) show how contextual factors, especially aspects related to teaching, can significantly influence a student to adopt a goal related to either mastery or performance. It is argued that if we want to improve the level at which our students engage in learning activities, and the likelihood that they will pursue mastery challenges, overcome the obstacles they face, and successfully complete academic activities, it is necessary to ask ourselves how it is possible for the teacher to develop actions to actualize motivational climates oriented toward mastery. To answer this question, however, it is necessary to know which specific action guidelines the teacher should change, which poses the problem of specifying the classroom motivational climate construct in an assessment instrument.

Among the different instruments that have been proposed to measure it, the Classroom Motivational Climate Questionnaire (CMCQ) (Alonso-Tapia \& Fernández-Heredia, 2008) stands out. This instrument gathers the ideas developed by Alonso-Tapia and Pardo (2006), in line with the approaches of Ames (1992) and Urdan and Turner (2005). The authors summarize a set of teaching strategies that can be organized around the different moments that occur during a class, and whose effectiveness has been shown to improve motivation toward learning. These strategies are summarized and shown in Figure 1. The CMCQ has been used widely in the Ibero-American context, showing adequate levels of reliability and a consistent theoretical structure; however, there are no reports of its use in Higher Education. The CMCQ can be applied simultaneously with the Attribution of Motivational Changes to the Teacher Questionnaire (AMCT-Q), which acts as a complementary questionnaire that allows identifying the students' attribution of degree of positive change experienced in their success expectancies, interest in the subject, perceived ability, effort disposition. self-regulation and satisfaction with teacher's work. 


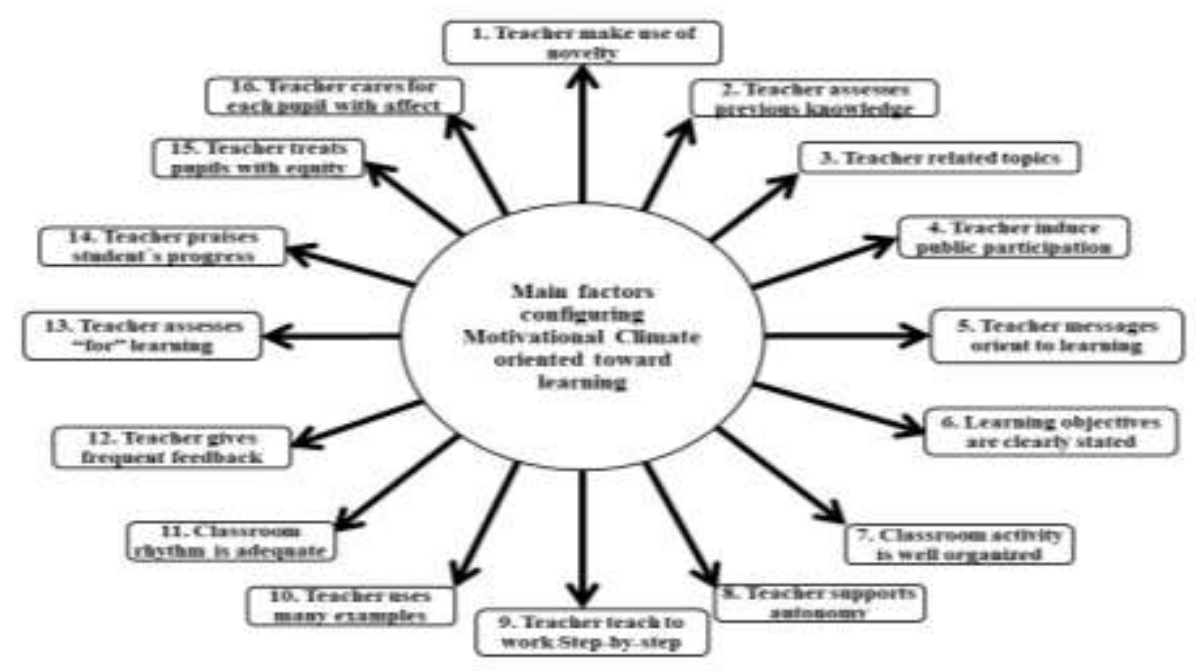

Figure 1

Classroom motivational climate elements (Alonso-Tapia, 2020)

Since neither of the two mentioned instruments has been validated in a Higher Education context, this study aims to adjust and validate the CMCQ and the AMCT-Q for its application in this context. The importance of the validation of the CMCQ at Higher Education relies on the fact that it would help teachers to identify their teaching patterns that are adequate for motivating the students, as well as those that should be modified due to their negative effects. As for the AMCTQ, it provides an index of changes that students attribute to professors and so is a validation measure that can be used in intervention studies. As for the starting hypotheses, they are based on the results that both instruments have produced in other contexts. First, we expect that adequate levels of structural validity will be reached, in line with the structure proposed by Alonso-Tapia and Fernández (2008; Alonso-Tapia, 2016), and that adequate values of reliability will be reached. Second, we expect to find differences between the preferences of Higher Education students and those of students at other educational levels. It is possible that students perceive motivational climates as more oriented toward performance, since the context of Higher Education classrooms is highly competitive, and students perceive a lot of pressure to perform, giving important weight to the grades obtained.

\section{METHOD}

\section{Sample}

A total of 624 students from the Universidad Pedagógica of Colombia participated in the study. They came from 38 different groups, all of which received classes in a total of 25 different subjects. Of the students, $94.6 \%$ were women, and $5.4 \%$ were men, between the ages of 17.1 and 40.5 years old $(M: 22.5 ; S D: 3.6)$, and $96.3 \%$ came from lower and 
middle-class backgrounds, and the percentages were representative of the university's population configuration.

\section{Instruments}

The Classroom Motivational Climate Questionnaire (CMCQ) (Alonso-Tapia \& Fernández-Heredia, 2008). The CMCQ is a 32-item questionnaire gathering 16 patterns of teacher action related to the beginning of the class, the development of the class, and the time the assessment is conducted. When used together, these patterns (Figure 1) invite the student to adopt mastery or learning goals (Alonso-Tapia \& FernándezHeredia, 2008). Teachers can use each pattern to a different degree, which, in turn, generates the classroom motivational climate. Each pattern is assessed through two items, one with a positive statement and the other with a negative statement, on a fivepoint Likert scale on which the student must indicate their degree of agreement. The quality of the questionnaire is substantiated by numerous studies conducted with more than 10,000 students in middle and higher school, and non-university adults; the studies collected are mostly by Alonso-Tapia (Alonso-Tapia et al 2020), with reliability indices ranging between .92 and .98

Attribution of Motivational Changes to the Teacher Questionnaire (AMCT-Q). The purpose of this questionnaire is to identify the degree to which the student attributes to the teacher the changes they have perceived in themselves throughout the class. This questionnaire complements the CMCQ in that the former allows for identifying the student's perception of the strategies the teacher employs in the classroom, whereas the AMCT-Q helps to identify the extent to which the student considers that these teacher strategies positively or negatively influence their progress in the classroom. It has six subscales to measure the degree to which change is attributed to the teacher: 1) in success expectancies; 2) in interest in the subject; 3 ) in perceived ability; 4) in effort disposition; 5) in self-regulation; 6) in satisfaction with teacher's work. It has been used in several studies, where adequate levels of reliability are reported in its scales, with values between .65 and .91 (Alonso-Tapia, et al, 2020; Leal-Soto \& Alonso-Tapia, 2017; Villasana \& Alonso-Tapia, 2015). Just as with CMCQ, the AMCT-Q has not been used or validated in a Higher Education population.

\section{Procedure}

Procedure for linguistic and cultural adjustment. The linguistic and cultural adjustment process was carried out based on the procedures described by Beaton, Bombardier, Guillemin, and Ferraz (2000) in four phases: 1) the review and adjustment of the instruments in their Spanish version by a group of experts; 2) a review of linguistic adjustments by the authors of the original version; 3 ) a pilot test with a group of finalyear university students; 4) a final review of the adjustments by the original authors.

Application procedure. Once the procedures are presented to the faculty research committee, the study was made known to teachers and students who were invited to participate voluntarily. The questionnaires were completed by the students on paper during the class. 


\section{Data Analysis}

Prior to conducting the analyses, cases with $5 \%$ or more of missing data were eliminated. In the remaining cases, where the missing data may be due to chance, these were replaced by the items mean score, a decision that generates less error.

Then, to discover the psychometric properties of the CMCQ and the AMCT-Q, confirmatory factorial analyzes were carried out to test the suitability of the model proposed for each questionnaire, and the models based on previous studies carried out in other countries, as described above. For the analysis, the sets of data were divided randomly into two subsamples. Factorial analysis was conducted on the first subsample, and the second sample was used to perform cross-validation that allows isolating the model's behavior once restrictions are imposed on the equality of parameters in the measurement weights. The estimation method used was Maximum Likelihood, and six model fit indices were considered: $\chi^{2} / \mathrm{gl}<5$; GFI, IFI, and CFI > 0.90; RMSEA < 0.08; SRMR $<0.08$. Once the model with the highest degree of fit was determined, a reliability analysis was performed using the Omega index (McDonald, 2013).

To study the questionnaires' concurrent/predictive validity, route analysis was used employing the CMCQ as predictor variable and the AMCT-Q and the final grade obtained in the course as criterion variables.

Finally, a multigroup analysis was carried out with two categories of students, those in their initial studies (basic) and those in practice-oriented studies (in-depth), with the purpose of determining whether the stage of study influenced both the measurement model and the validity of the instruments.

\section{FINDINGS AND DISCUSSION CMCQ Factorial Analysis}

Regarding the structure of the test, a single construct is observed as a classroom motivational climate toward learning manifested in the 16 action guidelines (Figure 2).

When observing the goodness-of-fit indicators shown in Table 1, we find that the model adequately fits the data. Although the p-value of $\chi^{2}$ is higher than expected, this is explained by the sample size, but $\chi^{2} / d f$ is less than 5 , so it is acceptable. The remaining indicators exceed acceptable fit values.

In the cross-validation analysis, acceptable values are also observed in all indicators, even when restrictions are imposed on the equality of parameters in the measurement weights $\left(\chi^{2}=20.026, p=0.171\right)$. Therefore, the model is well-estimated and can be accepted. The reliability score is high, $\omega=0.97$. The data show that the CMCQ is adequate and reliable for measuring classroom motivational climate in the Colombian Higher Education context and maintains the original structure posited by the authors. 


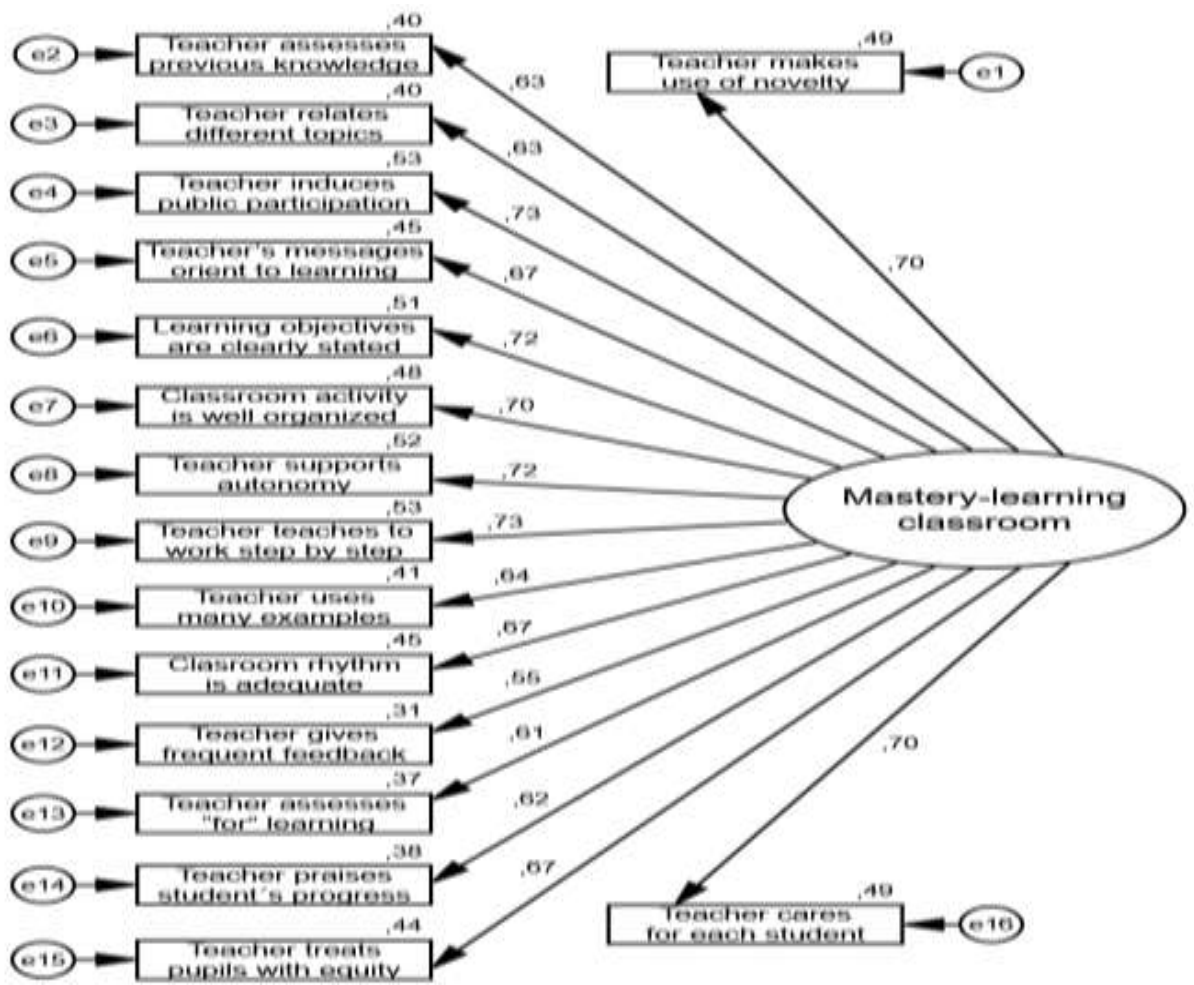

Figure 2

Original CMCQ model: Standardized measurement weights

Table 1

Goodness-of-fit indicators of CMCQ model

\begin{tabular}{lllllllll}
\hline AFC & $\chi^{2}$ & df & P & $\chi^{2} / \mathrm{df}$ & TL & CF & RMSEA & SRMR \\
& & & & & I & I & & \\
\hline $\begin{array}{l}\text { CMCQ original model } \\
N=314\end{array}$ & 260.69 & 105 & $<.001$ & 2.48 & .93 & .94 & .07 & .056 \\
\hline $\begin{array}{l}\text { CMCQ cross-validation } \\
N=314 / 313\end{array}$ & 546.35 & 225 & $<.001$ & 2.43 & .94 & .94 & .05 & .057 \\
\hline
\end{tabular}

\section{Factorial Analysis of the AMCT-Q}

Figure 3 shows the factor structure of the AMCT-Q. Table 2 shows the goodness-of-fit indicators that are adequate. Whereas the p-value of $\chi^{2}$ is higher than expected, this is explained by the sample size, but $\chi^{2} / d f$ is less than 5, so it is acceptable. 
Table 2

Goodness-of-fit indicators of the original AMCT-Q model and cross-validation analysis

\begin{tabular}{llllllllll}
\hline Analyses & $\chi^{2}$ & $\mathrm{df}$ & $\mathrm{P}$ & $\chi^{2} / d f$ & $\mathrm{TL}$ & $\mathrm{CFI}$ & $\mathrm{RMSEA}$ & SRMR \\
\hline Original model N=313 & 572.90 & 205 & $<.001$ & 2.80 & .92 & .92 & .08 & .05 \\
\hline $\begin{array}{l}\text { Cross-validation } \mathrm{N}=313 / \\
311\end{array}$ & 1123.33 & 436 & $<.001$ & 2.57 & .92 & .92 & .05 & .06 \\
\hline
\end{tabular}

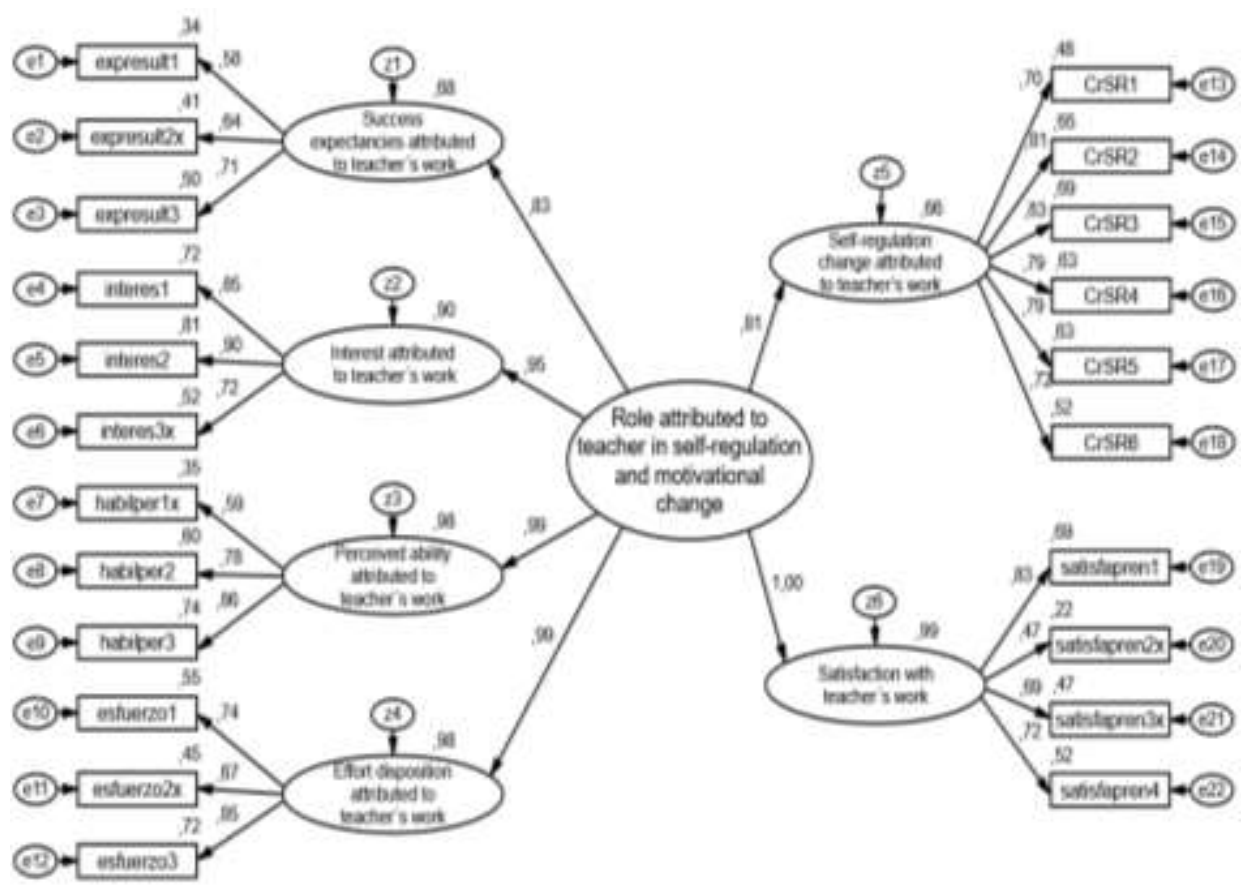

Figure 3

Original AMCT-Q model, standardized measurement and structural weights

The cross-validation multigroup analysis also shows acceptable values in all indicators, even when restrictions are imposed on equal parameters in measurement weights $\left(\chi^{2}=\right.$ 15.323, $p=0.501)$, in structural weights $\left(\chi^{2}=19.479, p=0.554\right)$, in structural covariances $\left(\chi^{2}=19.801, p=0.596\right)$, and in structural residuals $\left(\chi^{2}=22.827, p=\right.$ 0.643). Therefore, the model is well-estimated and can be accepted.

Regarding the reliability of the six scales and of the complete instrument, the indices are adequate, as can be seen in Table 3.

Overall, the data show that the structure of the AMCT-Q questionnaire corresponds to that expected and that its reliability is adequate, which allows this version to be accepted for use in research or intervention in the Colombian Higher Education context. 
Table 3

AMCT-Q reliability data based on the original model

\begin{tabular}{lll}
\hline Scale & Items & $\Omega$ \\
\hline Attribution of changes to the teacher (complete questionnaire) & 22 & .99 \\
\hline Success expectancies attributed to teacher's work & 3 & .85 \\
\hline Interest attributed to teacher's work & 3 & .89 \\
\hline Perceived ability attributed to teacher's work & 3 & .89 \\
\hline Effort disposition attributed to teacher's work & 3 & .88 \\
\hline Self-regulation change attributed to teacher's work & 6 & .94 \\
\hline Satisfaction with teacher's work & 4 & .85
\end{tabular}

Concurrent and Predictive Validity of the Classroom Motivational Climate Questionnaire in The Higher Education Context

To establish concurrent validity, the relationship of the CMCQ with the AMCT-Q as a whole was analyzed, while at the same time, its ability to predict academic performance was analyzed (final course note). For both purposes, a route analysis was performed using the AMCT-Q as a moderating variable and performance as a criterion. It was only possible to obtain the academic grades of 397 students. The reduction with respect to the original sample is because the system does not record the final grade due to enrollment problems, semester or course cancelation.

Figure 4 shows the prediction weights and Table 4 shows the fit indices. As can be seen, the data exhibit a good fit to the model, since all the indicators obtain values considered good, RMSEA being the only one that presents an acceptable value; therefore, we assume the model can be accepted. The relationship of the CMCQ with the AMCT-Q shows a $44 \%$ variance in common, which implies that students recognize the positive value of how teacher's respond (CMCQ) on the change in the different motivational indicators that were assessed by the AMCT-Q. In terms of predictive validity, the direct effect of CMCQ on performance is significant, but low (2.25\% variance explained), whereas the indirect effect is near to zero.

Table 4

Goodness-of-fit indicators of CMCQ predictive model on student satisfaction and academic performance

\begin{tabular}{lllllllll}
\hline Analysis & $\chi^{2}$ & $\mathrm{df}$ & $\mathrm{P}$ & $\chi^{2} / \mathrm{df}$ & TLI & CFI & RMSEA & SRMR \\
\hline $\begin{array}{l}\text { Predictive } \\
\text { Model N= 397 }\end{array}$ & 561.419 & 288 & $<.001$ & 2.46 & .937 & .943 & .061 & .040 \\
\hline
\end{tabular}




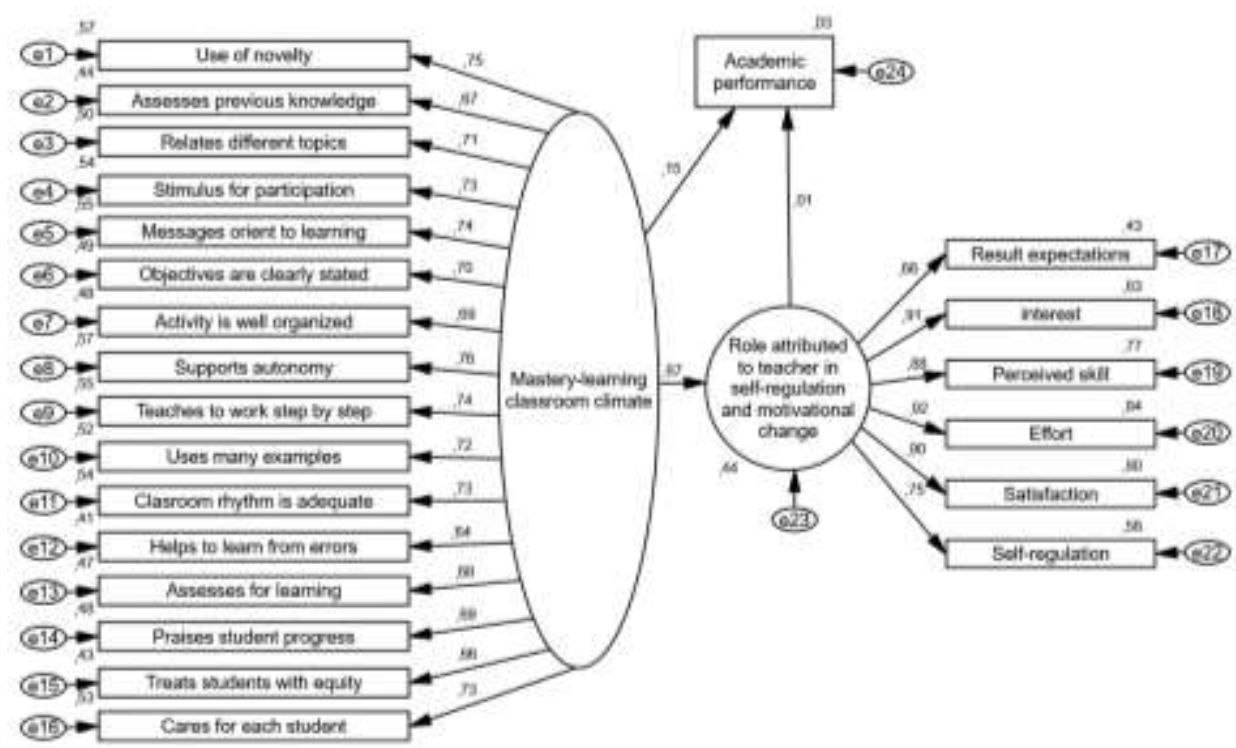

Figure 4

Predictive model of classroom motivational climate (16 scales) on student satisfaction and academic performance

\section{Analysis of the effect of the theoretical or practical orientation at the time of the studies}

A multigroup analysis was carried out to identify if there were differences between the students of the basic cycle (semesters 1 to 6 ) and those of the in-depth cycle (7 to 10). This division is specific to the university in the curricula, and marks the moment when students begin their internships, when they have to choose the path they will follow.

The fit indices (Table 5) are similar to those found with the sample used in the route analysis, which evidences that the model is adequate in both cases. However, there are differences when equality restrictions are imposed on measurement weights, which implies that not all classroom motivational climate indicators have the same value for students according to whether they are at one level of study or another. To see in which cases the differences occur, the $\mathrm{Z}$ statistic developed by Clogg, Petkova, and Haritou (1995) has been used.

Table 5

Indicators of goodness-of-fit of the multigroup analysis as a function of the theoretical or practical orientation of the level of studies

\begin{tabular}{lllllllll}
\hline Analysis & $\chi^{2}$ & $\mathrm{df}$ & $\mathrm{p}$ & $\chi^{2} / \mathrm{df}$ & $\mathrm{TLI}$ & CFI & RMSEA & SRMR \\
\hline $\begin{array}{l}\text { Multigroup analysis } \\
\mathrm{N}=244 \text { / 153 }\end{array}$ & 919.286 & \multirow{2}{*}{456} & $<.001$ & 2.016 & .915 & .923 & .051 & .047 \\
\hline
\end{tabular}


As can be seen in Table 6 , the data surpass the critical level $( \pm 1.96)$ in five cases. On the one hand, for initial-level students (basic), clarity of organization and relaxed pace is more related to a learning-oriented classroom climate than in the case of practiceoriented students (in-depth). For students at the higher level, the fact that the teacher indicating what will be learned by the students doing it and illustrating it with examples is more related to the perception of a climate oriented toward learning than in the case of students at the initial level.

Table 6

Analysis of differences between slopes. Z statistic by Clogg, et al. (1995)

\begin{tabular}{|c|c|c|c|c|c|c|c|}
\hline & & Basic & & In-deptl & & & \\
\hline Scales & & Estimate & S.E. & Estimate & S.E. & Diff. & $\mathrm{Z}$ \\
\hline Interest & $\longleftarrow$ AMCT & 1.00 & & 1.00 & & .00 & .00 \\
\hline Expectations of results & $\rightleftharpoons$ AMCT & .59 & .05 & .65 & .06 & -.06 & -1.10 \\
\hline Perceived skill & $\leftarrow$ AMCT & .84 & .04 & .86 & .05 & -.02 & -.50 \\
\hline Interest & $\longleftarrow$ AMCT & 1.00 & & 1.00 & & .00 & .00 \\
\hline Expectations of results & $\leftarrow$ AMCT & .59 & .05 & .65 & .06 & -.06 & -1.10 \\
\hline Perceived skill & $\longleftarrow$ AMCT & .84 & .04 & .86 & .05 & -.02 & -.50 \\
\hline Effort & AMCT & .91 & .04 & .89 & .05 & .02 & .57 \\
\hline Satisfaction & $\longleftarrow$ AMCT & .98 & .04 & .88 & .06 & .10 & 2.26 \\
\hline Self-regulation & $\longleftarrow$ AMCT & .72 & .05 & .66 & .06 & .06 & 1.28 \\
\hline New & $\longleftarrow \mathrm{CMC}$ & 1.00 & & 1.00 & & .00 & .00 \\
\hline Active previous knowledge & $\longleftarrow$ CMC & .86 & .07 & .71 & .09 & .15 & 1.75 \\
\hline Relates topics & $\longleftarrow \mathrm{CMC}$ & .78 & .07 & .92 & .10 & -.14 & -1.73 \\
\hline Promotes participation & $\longleftarrow \mathrm{CMC}$ & .84 & .07 & .94 & .10 & -.10 & -1.29 \\
\hline Messages toward learning & $\longleftarrow \mathrm{CMC}$ & .85 & .07 & 1.06 & .11 & -.21 & -2.53 \\
\hline Clarity of objective & $\longleftarrow \mathrm{CMC}$ & .98 & .08 & .85 & .10 & .14 & 1.46 \\
\hline Clarity of organization & $\longleftarrow \mathrm{CMC}$ & 1.01 & .09 & .80 & .09 & .21 & 2.26 \\
\hline Promotes autonomy & $\longleftarrow \mathrm{CMC}$ & .88 & .07 & .83 & .09 & .06 & .73 \\
\hline Teaches step by step & $\longleftarrow \mathrm{CMC}$ & 1.07 & .09 & .91 & .10 & .16 & 1.68 \\
\hline Provides examples & $\longleftarrow \mathrm{CMC}$ & .81 & .07 & 1.07 & .11 & -.27 & -3.15 \\
\hline Gives feedback & $\leftarrow \mathrm{CMC}$ & .84 & .08 & .99 & .11 & -.14 & -1.57 \\
\hline The pace is relaxed & $\longleftarrow \mathrm{CMC}$ & 1.09 & .08 & .58 & .08 & .51 & 6.02 \\
\hline Assesses for learning & $\leftarrow$ CMC & .89 & .09 & .83 & .11 & .05 & .55 \\
\hline Gives frequent praise & $\longleftarrow \mathrm{CMC}$ & .86 & .08 & .79 & .09 & .06 & .72 \\
\hline Treats everyone fairly & $\longleftarrow$ CMC & .80 & .07 & .74 & .10 & .06 & .71 \\
\hline Dedicates attention to each & $\leftarrow \mathrm{CMC}$ & .85 & .07 & .95 & .11 & -.09 & -1.12 \\
\hline
\end{tabular}


The fact that students value the teacher's impact on their own learning and motivation highly positively shows evidence in favor of the usefulness of the model. Each of the CMC scales investigates specific teaching patterns which importance for creating a CMC learning oriented has been suggested from authors of different theoretical orientations: behavioral theories, intrinsic motivation theories, and social-cognitive theorist (Patrick, Turner \& Strati, 2016). The suggested patterns have been integrated in the CMC following in some measure the sequence that instruction should follow with any kind of task. For example, the use of novel tasks that arouse curiosity and show their intrinsic and extrinsic value can favor students' engagement in the task; the activation of previous knowledge can help the students to feel that they have enough knowledge to perform the new task, which favor their sense of competence and their success expectancies. In a similar way, the remaining CMC patterns, if implemented by teachers, change the classroom dynamics, and can help to improve the student motivation to learn (Alonso-Tapia, 2016). These implications highlight the importance of the teacher's work in achieving high levels of quality in education. It shows clearly that it is necessary for Higher Education teachers to be attentive to the effect of their actions on student motivation as a key variable in the educational process.

An important element in achieving classroom motivational climates focused on learning is that the teacher presents a clear organization that allows the student to identify the course structure and learning objectives, in accordance with other studies carried out in Higher Education (Antoniou \& Kalinogloua, 2013; Senko, 2019).

Feedback on performance in class activities, autonomous work, and tests are valued highly by students and help them be more focused on learning than grades. These results gain importance in light of other research in the Higher Education context, in which the importance of feedback for the training of professional competencies is highlighted (Tai, Ajjawi, Boud, Dawson, \& Panadero, 2018). This aspect is relevant because, if the teacher only hands out the class notes and does not provide constant feedback for all activities, it leads the student to pursue purely performance objectives.

However, it is necessary to consider the point in their career where the student finds themself, because clearly, the value they give to the aspects of the class varies over time. It is important to mention the fact that, for initial-level students, their satisfaction is more closely linked with the actions taken by teachers. This may indicate the need for greater teacher support at this point in the student's career, an aspect that may progressively diminish in more advanced courses, where students show greater independence. This aspect may be related to students' age and the maturity acquired throughout their careers (Leal-Soto \& Alonso-Tapia, 2017).

Another aspect that should be considered is students' perception of the pace of the class, a guideline that shows the greater difference between initial and in-depth-level students, which shows the student's need to adapt to the pace of the class as they advance through their career. This aspect is related to research that identifies the increased demands in the university with respect to basic education as a dropout risk factor for first-year students (Harackiewicz, Barron, Tauer, \& Elliot, 2002). 
These results are especially relevant in light of other studies (Lerdpornkulrat, et al., 2018; Bardach, et al, 2019), whose results indicate that perceptions of classroom climate and instructional goal structures significantly influence students' motivational orientations and levels of commitment and engagement in their academic process, and that contributes to the intent to remain at the university. This opens the door to the creation of programs to improve teacher actions to favor classroom motivational climates focused on learning to reduce dropout rates, varying aspects of their teaching practice according to the point at which students find themselves in their career.

Finally, it should be highlighted that this study cannot generate conclusive findings on the relationship between the CMCQ and academic performance. The possible cause of this result is that only the final grade given by the teacher was used as a performance measure. It is important to consider this fact since, in the study, each course had different teachers and different ways of assessing and generating a final grade. Therefore, it is advisable to carry out other studies that lead to the identification of the impact of classroom motivational climate on aspects such as student self-efficacy and improving skills or knowledge identified through standardized tests.

\section{CONCLUSION}

Summarizing, it can be concluded that the Classroom Motivational Climate, when used with Colombian University students has the same structure shown in Figure 1 and found in previous studies, a structure supported for the results of CFA and reliability analyses (Alonso-Tapia \& Fernández-Heredia, 2008, Alonso-Tapia, et al, 2020; Leal-Soto \& Alonso-Tapia, 2017; Villasana \& Alonso-Tapia, 2015). Besides, the predictive validity with respect to changes in motivational variables has been quite good $-44 \%$ of variance explained-. This shows that teachers should pay attention to CMC teaching patterns in order to improve motivation: attribution of degree of positive changed experienced in their success expectancies, interest in the subject, perceived ability, effort disposition, self-regulation and satisfaction with teacher's work-. This result has also been found in the studies above cited, carried out with Spanish, Mexican, Chilean, and French students. Moreover, this study has allowed us to identify differences in the students' motivational profile depending on the course they were studying. These results indicate, on one side, that class organization and structure, and the possibility to learn at their own pace are characteristics that, the more increases, the more are valued as indicators of a CMC learning oriented by students during their first years. On the other side, the use of examples and of procedures that favor to learn step-by-step are more important for students of advanced levels. Therefore, we can assert that the instrument is reliable and valid in the case of the Colombian Higher Education population, and that it can be applied with confidence in research or intervention processes. The AMCT-Q also proves to be a reliable and valid instrument that can be applied with confidence for research or intervention processes at this level. Consequently, Higher Education teachers have two new instruments that make it easier for them to evaluate the perceived impact of their pedagogical practice in their student's motivation, which provides them with tools and theoretical bases to reflect on and improve their pedagogical practice. 


\section{REFERENCES}

Ahmad, I. \& Rana, S. (2011). Affectivity, achievement motivation, and academic performance in college students. Pakistan Journal of Psychological Research, 27(1), $107-120$.

https://pdfs.semanticscholar.org/6726/c1de93fe14b8c48c95ea3ee459c6e2cafbdc.pdf

Alonso-Tapia, J. (2016). Clima motivacional de clase: características, efectos y determinantes. [Classroom motivational climate: characteristics, effects, and determinants]. In: Veiga, F. H. (Coord.), Students' Engagement in School: Perspectives of Psychology and Education - Motivation for Academic Performance. (p. 9-34). Lisboa: Instituto de Educação da Universidad de Lisboa. Retrieved 29 March, 2020 from

http://www.ie.ulisboa.pt/publicacoes/envolvimento-dos-alunos-na-escola-perspetivasda-psicologia-e-educacao-motivacao-para-o-desempenho-academico

Alonso-Tapia, J. \& Fernández-Heredia, B. (2008). Development and initial validation of the Classroom Motivational Climate Questionnaire (CMCQ). Psicothema, 20(4), 883889. 29 Retrieved 29 March, 2020 from https://www.researchgate.net/publication/23404382_Development_and_initial_validatio n_of_the_Classroom_Motivational_Climate_Questionnaire_CMCQ

Alonso-Tapia, J., Ruiz, M. Á. \& Huertas, J. A. (2020). Differences in classroom motivational climate: causes, effects and implications for teacher education. A multilevel study. Anales De Psicología/Annals of Psychology, 36(1), 122-133. https://doi.org/10.6018/analesps.336681

Alonso-Tapia, J. \& Pardo, A. (2006). Assessment of learning environment motivational quality from the point of view of secondary and high school learners. Learning and Instruction, 16(4), 295-309. http://doi.org/10.1016/j.learninstruc.2006.07.002

Ames, C. (1992). Achievement goals and the classroom motivational climate. In D. H. Schunk \& J. L. Meece (Eds.), Student perceptions in the classroom. (pp. 327-348).

Ames, C. \& Archer, J. (1988). Achievement goals in the classroom: Students' learning strategies and motivation processes. Journal of Educational Psychology, 80(3), 260267. https://doi.org/10.1037/0022-0663.80.3.260

Anderson, C. S. (1982). The search for school climate: A review of the research. Review of Educational Research, 52(3), 368-420. https://doi.org/10.3102/00346543052003368

Antoniou, F. \& Kalinogloua, F. (2013). Teaching Style: Is it measurable and changeable?. Procedia-Social and Behavioral Sciences, 93, 1618-1623. https://doi.org/10.1016/j.sbspro.2013.10.090

Bardach, L., Oczlon, S., Pietschnig, J. \& Lüftenegger, M. (2019). Has achievement goal theory been right? A meta-analysis of the relation between goal structures and personal achievement goals. Journal of Educational Psychology. http://dx.doi.org/10.1037/edu0000419 
Beaton, D. E., Bombardier, C., Guillemin, F. \& Ferraz, M. B. (2000). Guidelines for the process of cross-cultural adaptation of self-report measures. Spine, 25(24), 3186-3191.

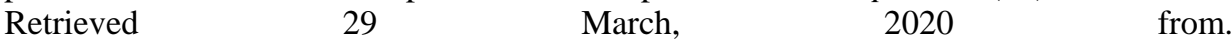
http://staff.ui.ac.id/system/files/users/andisk/material/guidelinesfortheprocessofcrosscult uraladaptation.pdf

Cellar, D. F., Stuhlmacher, A. F., Young, S. K., Fisher, D. M., Adair, C. K., Haynes, S., Twichell, E., Arnold, K.A., Royer, K., Denning, B.L. \& Riester, D. (2011). Trait goal orientation, self-regulation, and performance: A meta-analysis. Journal of Business and Psychology, 26(4), 467-483. http://doi.org/10.1007/s10869-010-9201-6

Clogg, C. C., Petkova, E., \& Haritou, A. (1995). Statistical methods for comparing regression coefficients between models. American journal of sociology, 100(5), 12611293. https://doi.org/10.1086/230638

Corkin, D. M., Horn, C. \& Pattison, D. (2017). The effects of an active learning intervention in biology on college students' classroom motivational climate perceptions, motivation, and achievement. Educational Psychology, 37(9), 1106-1124. https://doi.org/10.1080/01443410.2017.1324128

Djigic, G. \& Stojiljkovic, S. (2011). Classroom management styles, classroom climate and school achievement. Procedia-Social and Behavioral Sciences, 29, 819-828. https://doi.org/10.1016/j.sbspro.2011.11.310

Goldenberg, J. \& Klavir, R. (2017). School Climate, Classroom Climate, and Teaching Quality: Can Excellent Students Unravel this Connection? International Journal for Talent Development and Creativity, 5(2), 137-148. www.icieworld.net

Gutiérrez, M. \& Tomás, J.-M. (2018). Motivational class climate, motivation and academic success in university students. Revista de Psicodidáctica, 23(2), 94-101. https://doi.org/10.1016/j.psicod.2018.02.001

Harackiewicz, J. M., Barron, K. E., Tauer, J. M. \& Elliot, A. J. (2002). Predicting success in college: A longitudinal study of achievement goals and ability measures as predictors of interest and performance from freshman year through graduation. Journal of Educational Psychology, 94(3), https://doi.org/562.10.1037//0022-0663.94.3.562

Kadioglu, C. \& Uzuntiryaki-Kondakci, E. (2014). Relationship between Learning Strategies and Goal Orientations: A Multilevel Analysis. Eurasian Journal of Educational Research, 56, 1-22. https://doi.org/10.14689/ejer.2014.56.4

Kelmendi, N. \& Nawar, Y. S. (2016). Assessing the impact of motivation on student retention: the case of University of West London. The Business \& Management Review, 7(5), 67-78. $\quad$ Retrieved 29 March, 2020 from https://cberuk.com/cdn/conference_proceedings/conference_48601.pdf

Leal-Soto, F. \& Alonso-Tapia, J. (2017). Cuestionario de Clima Motivacional de la Clase: Validez Intercultural, Intergénero, Evolutiva y Predictiva [Classroom Motivational Climate Questionnaire: Intercultural, Intergovernmental, Evolutionary, and 
Predictive Validity]. Avaliação Psicológica, 3(45), 57-70. https://doi.org/10.21865/RIDEP45.3.05

Lerdpornkulrat, T., Koul, R., \& Poondej, C. (2018) Relationship between perceptions of classroom climate and institutional goal structures and student motivation, engagement and intention to persist in college, Journal of Further and Higher Education, 42(1), 102-115. https://doi.org/10.1080/0309877X.2016.1206855

McDonald, R. P. (2013). Test theory: A unified treatment. Psychology Press.

Meece, J. L., Anderman, E. M. \& Anderman, L. H. (2006). Classroom goal structure, student motivation, and academic achievement. Annual Review of Psychology, 57, 487503. https://doi.org/10.1146/annurev.psych.56.091103.070258

Nicholls, J. G. (1989). The competitive ethos and democratic education. Harvard University Press.

Patrick, H., Kaplan, A. \& Ryan, A. M. (2011). Positive classroom motivational environments: Convergence between mastery goal structure and classroom social $\begin{array}{llll}\text { climate. Journal of Educational Psychology, 103(2), } 367 . & .\end{array}$ https://doi.org/10.1037/a0023311

Patrick, H., Turner, J.C., \& Strati, A.D. (2016). Classroom and school level influences on student motivation. In K. Wentzel \& G.B. Ramani (Eds.), Handbook of social influences in school contexts: Social-emotional, motivation, and cognitive outcomes (pp. 241-257). New York: Routledge.

Rolland, R.G. (2012). Synthesizing the evidence on classroom goal structures in middle and secondary schools: A meta-analysis and narrative review. Review of Educational Research, 82(4), 396-435. https://doi.org/10.3102/0034654312464909

Senior, R.M., Bartholomew, P., Soor, A., Shepperd, D., Bartholomew, N. \& Senior, C. (2018). The Rules of Engagement: Student Engagement and Motivation to Improve the Quality of Undergraduate Learning. Frontiers in Education, 3(32), 1-9. https://doi.org/10.3389/feduc.2018.00032

Senko, C. (2019). When do mastery and performance goals facilitate academic achievement? Contemporary Educational Psychology, 59, 101795. https://doi.org/10.1016/j.cedpsych.2019.101795

Tai, J., Ajjawi, R., Boud, D., Dawson, P., \& Panadero, E. (2018). Developing evaluative judgment: enabling students to make decisions about the quality of work. Higher Education, 76(3), 467-481. https://doi.org/10.1007/s10734-017-0220-3

Urdan, T. \& Turner, J.C. (2005). Competence Motivation in the Classroom. En Elliot, A. J \& Dweck, C.S. Handbook of competence and motivation. (pp. 297-317). Gilford Press.

Vandewalle, D., Nerstad, C. G. \& Dysvik, A. (2019). Goal orientation: A review of the miles traveled and the miles to go. Annual Review of Organizational Psychology and 
Organizational Behavior, 6, 115-144. https://doi.org/10.1146/annurev-orgpsych041015-062547

Villasana, M. \& Alonso-Tapia, J. (2015). Validez transcultural del Cuestionario de Clima Motivacional de Clase: Comparación entre estudiantes franceses y españoles [Cross-Cultural Validity of the Classroom Motivational Climate Questionnaire: Comparison between French and Spanish Students]. Revista de Psicodidáctica, 20(2), 227-246. https://doi.org/10.1387/RevPsicodidact.13034

Zlate, S. \& Cucui, G. (2015). Motivation and performance in Higher Education. Procedia-Social and Behavioral Sciences, 180, 468-476. https://doi.org/10.1016/j.sbspro.2015.02.146 